\title{
Finger Force Coordination Underlying Object Manipulation in the Elderly - A Mini-Review
}

\author{
Gudrun Diermayr Tara L. Mclsaac Andrew M. Gordon \\ Department of Biobehavioral Sciences, Teachers College, Columbia University, New York, N.Y., USA
}

\section{Key Words}

Aging · Fingertip force - Precision grip $\cdot$ Hand motor control $\cdot$ Grasp control

\begin{abstract}
Background: A decline in manual dexterity is a common phenomenon in elderly individuals. Often, simple daily activities such as handling coins and preparing meals become challenging. A substantial decline in manual dexterity may impact one's ability to live independently. Thus, understanding the underlying causes of these impairments is essential. Considerable attention has been given to the regulation of fingertip forces during object grasp, lift and transport in the elderly. Objective: Here we review studies on fingertip force coordination in the elderly, with an emphasis on the relationship between the degree of change in elderly grip force control and the nature of the tasks performed. Methods: A literature search was performed using Medline, Pubmed, and Web of Science electronic databases covering studies from 1985 to 2009, inputting combinations of the following key words: grip force, grasp force, fingertip forces, precision grip, aging, elderly, and hand motor control. Results: Studies show a consistent elevation in grip force magnitudes that may easily lead to fatigue. These force increases may represent a compensation for increased skin slipperiness or a re-
\end{abstract}

duction in tactile information. In contrast, anticipatory grip force control (planning) remains relatively intact. Age-related changes in anticipatory control seem to emerge only during more complex tasks. Conclusion: The relationship between task complexity and degree of age-related changes suggests that results from simple, laboratory-based tasks may only partially explain impairments observed during the performance of activities of daily living, since the latter ones are typically more complex. A better understanding of impaired manual dexterity experienced by elderly individuals could be achieved by expanding experimental paradigms so that they more closely resemble the complexities encountered in functional daily tasks. Subsequently, these findings could be used in clinical settings to develop treatment approaches that consider grasp control in the context of behaviorally meaningful tasks. Copyright $\odot 2010$ S. Karger AG, Basel

\section{Introduction}

A decline in manual dexterity is a common phenomenon in elderly individuals $[1,2]$. Often, daily activities such as handling coins and preparing meals are impaired $[1,3]$. Functional assessment of manual dexterity used in the clinic confirms the reported impairments in daily

\section{KARGER \\ Fax +4161306 1234 \\ E-Mail karger@karger.ch}

www.karger.com
(C) 2010 S. Karger AG, Basel

0304-324X/11/0573-0217\$38.00/0

Accessible online at:

www.karger.com/ger
Andrew M. Gordon, $\mathrm{PhD}$

Department of Biobehavioral Sciences, Box 199

Teachers College, Columbia University, 525 West 120th Street

New York, NY 10027 (USA)

Tel. +1 212678 3326, Fax +1 212678 3322, E-Mail ag275@ columbia.edu 
manual tasks. For example, the Purdue Pegboard [4] (or adapted versions of it [2]), the Jebsen-Taylor Hand Function Test [5], and the Upper Extremity Performance Test for the Elderly [6] all demonstrate that elderly adults take longer time to complete these functional tasks. Moreover, Shiffman [7] showed that, in addition to being slower, elderly adults re-adjust their hand position on the grasped object more often and demonstrate greater variations in their prehension patterns (e.g. tripod pinch, lateral pinch) compared to young adults when retrieving coins from a purse or pouring milk from a container.

A substantial decline in manual dexterity impacts one's ability to live independently as shown by a tight link between impaired manual dexterity and a reduced ability to perform activities of daily living [8] or the likelihood of being admitted to a nursing home [9]. Thus, it is important to gain an understanding of the underlying causes of impaired manual dexterity and to subsequently incorporate such knowledge into evidence-based prevention and rehabilitation approaches. In addition to muscle strength, and sensory and anatomical integrity of the hand $[2,6,7,10]$, a prerequisite for activities involving object handling is the precise control of fingertip forces (i.e., grasp control). In this review, we summarize studies of grip force control underlying object grasp, lift and transport in the elderly. Following a brief summary of the basic neuromotor processes underlying grasp control in young adults, we review findings on grasp control in the elderly by drawing links between the behavioral grasp data and known physiological changes of the aging hand. The relationship between the degree of change in elderly grasp control and the nature of the tasks performed are highlighted. Finally, we point out future research directions that may be useful in explaining the effects of aging on manual dexterity.

\section{Background: Neuromotor Processes Underlying Successful Grasp Control}

Successful and efficient object manipulation requires precise modulation and temporal control of fingertip forces. This has largely been studied by examining fingertip forces during a simple grasp, lift and hold paradigm. Such studies in young healthy individuals have been extensively reviewed elsewhere [11]. Here we briefly summarize the control of this task to provide context for our subsequent review of grasp control in the elderly.

Object lift and hold can be subdivided into 4 distinct temporal phases [12]. During the 'preload phase', the dig- its contact the object and a small grip force (i.e., normal to the surface) is established before the onset of vertical load force (i.e., tangential to the surface). In the subsequent 'loading phase', the grip force increases in parallel with the load force until the load force exceeds the gravitational forces acting on the object and lift-off occurs. The 'transitional phase' begins at lift-off and continues until the object is transported to its desired position. The grip and load forces reach their peak values during this phase. The 'static phase' is achieved after approximately $1 \mathrm{~s}$ when a steady level of grip force is reached when the object is held in the air.

During the lifting and subsequent holding, the magnitude of grip force is adjusted to the object's physical properties, including its weight, center of mass location and frictional condition (i.e., slipperiness) at the digitobject interface $[12,13]$. If grip forces are insufficient, the hold on the object may be lost. Conversely, excessive grip forces may result in premature muscular fatigue, crushing of fragile objects, or difficulties in manipulations superimposed on the basic grasp [12]. Healthy young participants use grip forces just slightly above the force necessary to prevent object slippage (i.e., they employ a 'safety margin'), indicating an energy-efficient strategy to maintain object stability [12].

\section{Anticipatory Grip Force Control}

Since there is a delay in sensing relevant feedback signaling object texture and weight, the initial force scaling during the loading phase is based on internal memory representations of these properties acquired during prior manipulatory experience with the object or similar ones [6]. Visual information can be used to recall memory representations or indicate object size and mass distribution to estimate the appropriate fingertip force scaling $[14,15]$. These representations are particularly important in the absence of meaningful visual cues, when object weight or texture are unknown to the participants or are varied randomly between lifts. This process of scaling fingertip forces prior to availability of somatosensory signals is a form of higher-level motor planning and is referred to as anticipatory control.

In addition to the object's physical properties, the central nervous system also takes into account forces that act on the object as a result of object movement (i.e., inertial forces). When transporting an object (e.g. during arm or whole-body movements), the grip forces fluctuate in parallel with the movement-induced inertial forces and are coupled closely in time $[16,17]$. This coupling indicates that the central nervous system predicts the inertial force 
changes and regulates grip force in an anticipatory manner [16] similar to the control mechanisms in object grasp and lift described above. Thus anticipatory control mechanisms are a central feature of grasp control and are essential for dexterous behaviors.

\section{Feedback Mechanisms Associated with Grip Force Magnitude Adaptation}

In addition to anticipatory control, feedback mechanisms, including information from visual, proprioceptive, and tactile systems are involved in successful grasping, particularly in the forming and maintenance of predictive control processes [11]. The visual system plays a key role in the identification of object properties and in the retrieval of memory representations [14]. In the adaptation of grip force magnitude and in the ability to maintain a low safety margin, vision becomes less important since the fingertip forces and mechanical interactions (i.e., micro-slips) cannot be visualized. Similarly, the proprioceptive system does not provide substantial information about mechanical events at the object-digit interface occurring during object contact $[11,18,19]$. Such information is provided directly by tactile afferents; hence, for grip force magnitude adaptation, tactile feedback is crucial $[11,18]$. The subsequent discussion will therefore focus on tactile feedback involved in the adaptation of grip force magnitude.

Tactile afferent fibers in the fingertips encode information pertaining to object friction, shape and force direction [11]. When object properties are unknown, information pertaining to friction can be used already $100 \mathrm{~ms}$ after finger contact [12]. Moreover, in the case of erroneous grip force employment (e.g. forces being too low when the object is more slippery than expected), such feedback provides the basis for force correction by modifying the motor command (e.g. by increasing grip force) to prevent slip [12]. Importantly, the information obtained by tactile afferents related to object properties is also used to form and update the memory representations used for anticipatory control during subsequent object lifts [12].

When sensory information is eliminated by anesthetizing the finger pads, the frictional properties of the object are not detected and the appropriate modulation of grip forces to friction does not occur [12]. Instead, participants employ higher grip force safety margins during object lift and point-to-point movements [12, 20]. For example, Nowak et al. [20] showed that healthy young adults whose fingers were anesthetized increased the grip-load force ratio by between 90 and $260 \%$ during vertical pointto-point arm movements with a hand-held object. These increases indicate that participants employed a higher grip force safety margin during object movement [20]. Therefore, the lack of tactile sensation (in this case through anesthesia) is associated with inefficient grip force modulation. The lack of tactile sensation also leads to an increased duration of the preload and loading phases suggesting that tactile signals are normally used to trigger the transition between these phases [6]. In contrast, the temporal coupling of grip and load forces during arm movements is not impaired in the absence of tactile information, indicating only a minor role of tactile information in anticipatory force coupling [20]. Overall, these findings emphasize the importance of tactile information in efficient grip force modulation, especially when object properties are unknown. As described below, this is important in light of sensory changes in the skin with aging.

In summary, successful grip force control in predictable tasks is an interplay between anticipatory and feedback mechanisms relying on internal representations of the task and sensory information, respectively. While this review focuses on grip force control during self-initiated object handling, it is important to note that when changes in the object's inertial properties are externally triggered and/or unexpected, considerable delays in grip force adjustments occur, suggesting the reliance on feedback mechanisms to successfully accomplish the task [21, 22]. Next we consider these mechanisms in relation to aging.

\section{Data Sources and Literature Selection}

We conducted a literature search on grip force control underlying object handling in the elderly using Medline, Pubmed, and Web of Science electronic databases covering studies from 1985 to 2009, inputting combinations of the following key words: grip force, grasp force, fingertip forces, precision grip, aging, elderly, and hand motor control. In addition to the electronic search, we handsearched the reference lists of the articles meeting the search criteria. In one case, we found a book chapter reporting preliminary data on elderly grasp control, and subsequently queried the author about the stage of this work. We received an advance copy of the paper which is now in press. The search procedure ended on October 1, 2009. Only studies in English were included. Since the focus of this review is on grip force control during object grasp, lift and transport, we excluded studies whose experimental tasks involved a finger-hand position atypical 
for grasp and finger individuation (e.g. pronated hand position without thumb opposition). Nineteen articles met our criteria, and are listed in table 1.

\section{Fingertip Force Control in the Elderly}

As reviewed in detail in the following sections, healthy elderly individuals use excessive grip forces compared to the young during object manipulations. However, anticipatory grip force control is relatively intact, at least during simple object manipulation. While the finding of excessive grip force magnitudes is well established, findings on anticipatory control are less consistent. Additional parameters of grasp control that are affected by aging include temporal aspects of force coordination and the ability to control force moments acting on the object. Moreover, as described below, the grip force profiles of the elderly have been found to be more variable.

\section{Age-Related Changes in Grip Force Scaling}

Increased grip force and/or grip force safety margin is by far the most consistent age-related change in grasp control across studies. The grip forces in the elderly are excessive during both static $[23,24]$ and dynamic tasks [25], and during continuous [25] and discrete [26] tasks. Moreover, the increase in force was observed irrespective of object properties $[27,28]$, the number of digits involved (2- versus multi-digit grasp) $[29,30]$, the predictability of the task [29,31], and whether participants were seated or standing [32]. Comparisons of young, middleaged and elderly participants by Cole et al. [29] and Lindberg et al. [24] indicated that increases in grip force magnitude during object manipulation begin as early as 50 years of age.

The grip force increases during early aging are proposed to be a function of age-related changes in the skin. A reduction of the water content in the outermost layer of the skin [33] makes the skin drier and may in turn decrease the friction at the object-digit interface. The consequence of these skin changes is an increased slipperiness of the fingers during object handling, increasing the likelihood of dropping the object. This proposal is supported by studies showing that the slip force (i.e., the minimum force required to prevent an object from slipping) is increased in the elderly [26-29,34]. The lower the friction at the object-digit interface (due to either a slippery object surface or increased skin slipperiness), the higher the grip forces necessary to maintain object stability [12]. Indeed, the increased grip force during early ag- ing is in proportion to the elevated slip forces [27, 29], whereby the safety margin does not differ.

With advancing age, the employed safety margin is elevated additionally [25-30], indicating a grip force increase beyond what is necessary to compensate for increased slipperiness. The increased safety margin has been attributed to the age-related deterioration of sensory processing at the fingertips [2, 23, 25, 27-29]. Increasing the grip force safety margin reduces the dependence on sensory signals $[27,28]$ as it prevents potential slips. Agerelated reductions in number and in size of the mechanoreceptors are well documented $[35,36]$. Moreover, with advancing age sensory signals are attenuated due to an increased threshold needed for the generation of action potentials [36]. Clinical evaluation of mechanoreceptor function of the hand shows that the elderly typically have increased thresholds for detecting minimal mechanical forces at the fingertips $[1,29,31,37]$ and for 2-point discrimination $[1,2,27]$. Moreover, these impairments are correlated with deficits in manual dexterity such as turning over cards (one component of the Jebsen-Taylor Hand Function Test [27]) and placing a peg in a pegboard [2]. This highlights the role of tactile sensation mediated by mechanoreceptors in tasks requiring manual dexterity.

The close relationship between grip force increases and reduced availability of friction-related sensory information becomes more apparent in adults 60 years of age and older [29]. These participants used higher safety margins when surface texture was changed randomly, but not when the object weight was varied, indicating selectively impaired detection of friction. These participants also used a default grip force level scaled to the most slippery surface, suggesting a strategy less dependent on sensory information [29].

Taken together, these findings imply that increased grip forces and/or grip force safety margins represent a compensatory strategy for increased skin slipperiness or reduced tactile information from the fingertips. This seems to be beneficial functionally in that it decreases the likelihood of object dropping. On the other hand, increased grip forces could lead to impaired dexterity in tasks requiring force coordination at low levels because of increased muscle activation [27]. Moreover, increased levels of muscle activation associated with increased grip forces are less energy-efficient and may result in premature fatigue [38], a possible contributor to increased motor variability [39].

Indeed, the higher grip forces in the elderly are prone to be more variable. At low target force levels or long task durations, age-related differences are apparent in 2-digit 
Table 1. Data sources and literature selection

\begin{tabular}{|c|c|c|c|c|}
\hline $\begin{array}{l}\text { Authors and } \\
\text { year }\end{array}$ & Age, years ${ }^{1}$ & Topic & Measurement and task & Main finding in elderly \\
\hline $\begin{array}{l}\text { Ranganathan } \\
\text { et al. [2], } 2001\end{array}$ & $\begin{array}{l}70.5 \\
65-79\end{array}$ & $\begin{array}{l}\text { GF scaling } \\
\text { Force variability }\end{array}$ & $\begin{array}{l}\text { Hand grip strength, maximum pinch } \\
\text { force, ability to maintain steady force } \\
\text { at submaximal levels, precision pinch } \\
\text { posture }\end{array}$ & $\begin{array}{l}\downarrow \text { Hand grip strength } \\
\downarrow \text { Maximum pinch force } \\
\downarrow \text { Ability to maintain steady force at submaximal } \\
\text { levels } \\
\downarrow \text { Precision pinch posture }\end{array}$ \\
\hline $\begin{array}{l}\text { Cole and Beck } \\
{[23], 1994}\end{array}$ & $\begin{array}{l}77 \\
68-85\end{array}$ & $\begin{array}{l}\text { GF scaling } \\
\text { Force variability }\end{array}$ & $\begin{array}{l}\text { GF magnitudes and within-trial GF } \\
\text { variability during grasp, lift and hold } \\
\text { of small objects in precision grasp, } \\
\text { and during 2-digit submaximal force } \\
\text { maintenance }\end{array}$ & $\begin{array}{l}\uparrow \mathrm{GF} \\
\text { No age effect on GF variability in both tasks }\end{array}$ \\
\hline $\begin{array}{l}\text { Lindberg et al. } \\
{[24], 2009}\end{array}$ & $\begin{array}{l}41 \\
21-67\end{array}$ & $\begin{array}{l}\text { GF scaling } \\
\text { Force variability } \\
\text { Temporal aspects of } \\
\text { grasp control }\end{array}$ & $\begin{array}{l}\text { GF coordination (precision and } \\
\text { performance) in isometric 2-digit } \\
\text { precision grip ramp-and-hold force } \\
\text { tracking task at submaximal force } \\
\text { levels }\end{array}$ & $\begin{array}{l}\uparrow \mathrm{GF} \\
\downarrow \text { Precision starts in middle age } \\
\text { Age correlated with error at lowest force levels } \\
\text { (not at higher levels) }\end{array}$ \\
\hline $\begin{array}{l}\text { Danion et al. } \\
{[25], 2007}\end{array}$ & $\begin{array}{l}66 \pm 3.6 \\
61-74\end{array}$ & $\begin{array}{l}\text { GF scaling } \\
\text { Anticipatory control }\end{array}$ & $\begin{array}{l}\text { GF/IF coordination during cyclic } \\
\text { anterior-posterior arm movements } \\
\text { with object under various external } \\
\text { load fields }\end{array}$ & $\begin{array}{l}\uparrow \mathrm{GF} \\
\text { Intact but less efficient GF/IF coupling when IF } \\
\text { varied twice the movement frequency }\end{array}$ \\
\hline $\begin{array}{l}\text { Gilles and Wing } \\
{[26], 2003}\end{array}$ & $\begin{array}{l}64.5 \pm 3.8 \\
59-70\end{array}$ & $\begin{array}{l}\text { GF scaling } \\
\text { Anticipatory control }\end{array}$ & $\begin{array}{l}\text { GF/LF coordination during vertical } \\
\text { point-to-point movement with object }\end{array}$ & $\begin{array}{l}\uparrow \mathrm{GF} \\
\uparrow \text { Slip force } \\
\text { GF modulated in parallel with changes in load }\end{array}$ \\
\hline Cole [27], 1991 & $\begin{array}{l}81 \\
71-92\end{array}$ & $\begin{array}{l}\text { GF scaling } \\
\text { Anticipatory control } \\
\text { Temporal aspects of } \\
\text { grasp control }\end{array}$ & $\begin{array}{l}\text { GF/LF coordination in grasp and lift } \\
\text { of objects of varying weight and } \\
\text { friction }\end{array}$ & $\begin{array}{l}\uparrow \mathrm{GF} \\
\uparrow \text { Slip force } \\
\uparrow \mathrm{SM} \\
\text { GF scaled to object properties, experience from } \\
\text { previous trial used for scaling in subsequent trial }\end{array}$ \\
\hline $\begin{array}{l}\text { Kinoshita and } \\
\text { Francis [28], } \\
1996\end{array}$ & $\begin{array}{l}2 \text { elderly groups: } \\
74.5 \pm 3.8 \\
69-79 \\
86.4 \pm 4.4 \\
81-93\end{array}$ & $\begin{array}{l}\text { GF scaling } \\
\text { Anticipatory control } \\
\text { Temporal aspects of } \\
\text { grasp control }\end{array}$ & $\begin{array}{l}\text { GF/LF coordination in grasp and lift } \\
\text { of objects of varying friction }\end{array}$ & $\begin{array}{l}\uparrow \mathrm{GF} \\
\uparrow \text { Slip force } \\
\uparrow \mathrm{SM} \\
\text { GF scaled to object properties } \\
\uparrow \text { Preload and loading durations }\end{array}$ \\
\hline $\begin{array}{l}\text { Cole et al. [29], } \\
1999\end{array}$ & $\begin{array}{l}3 \text { elderly groups: } \\
54 \\
48-58 \\
65.7 \\
60-69 \\
77.1 \\
71-86\end{array}$ & $\begin{array}{l}\text { GF scaling } \\
\text { Anticipatory control } \\
\text { Temporal aspects of } \\
\text { grasp control }\end{array}$ & $\begin{array}{l}\text { GF/LF coordination in grasp and lift } \\
\text { of objects of varying weight and } \\
\text { friction }\end{array}$ & $\begin{array}{l}\uparrow \mathrm{GF} \\
\uparrow \text { Slip force starting at age } 50 \\
\uparrow \mathrm{SM} \text { starting at age } 60 \\
\text { GF scaled to object properties, experience from } \\
\text { previous trial used for scaling in subsequent trial }\end{array}$ \\
\hline $\begin{array}{l}\text { Shim et al. [30], } \\
2004\end{array}$ & $\begin{array}{l}\text { Females: } 78.3 \pm 2.9 \\
\text { Males: } 86.7 \pm 9.6\end{array}$ & $\begin{array}{l}\text { GF scaling } \\
\text { Force variability } \\
\text { Force moments } \\
\text { and directions }\end{array}$ & $\begin{array}{l}\text { Finger force coordination in constant } \\
\text { moment production and ramp force } \\
\text { production in } 5 \text {-digit grasp }\end{array}$ & $\begin{array}{l}\uparrow \mathrm{GF} \\
\uparrow \text { Variability of force and moment in both tasks } \\
\uparrow \text { Antagonistic moment }\end{array}$ \\
\hline $\begin{array}{l}\text { Cole and } \\
\text { Rotella [31], } \\
2001\end{array}$ & $\begin{array}{l}77.8 \\
70-88\end{array}$ & $\begin{array}{l}\text { Temporal aspects of } \\
\text { grasp control }\end{array}$ & $\begin{array}{l}\text { GF/LF coordination (timing) during } \\
\text { stabilization of handle with } \\
\text { unexpected load changes }\end{array}$ & $\begin{array}{l}\uparrow \mathrm{GF} \\
\uparrow \mathrm{SM} \\
\uparrow \mathrm{GF} \text { response latencies when load changes small } \\
\text { and gradual }\end{array}$ \\
\hline $\begin{array}{l}\text { Mallau and } \\
\text { Simoneau [32], } \\
2009\end{array}$ & $\begin{array}{l}68.11 \pm 5.4 \\
62-71\end{array}$ & GF scaling & $\begin{array}{l}\text { GF magnitude scaling and GF/LF } \\
\text { coordination during object lift in } \\
\text { sitting and standing }\end{array}$ & $\uparrow \mathrm{GF}$ during standing and sitting \\
\hline $\begin{array}{l}\text { Lowe [34], } \\
2002\end{array}$ & $\begin{array}{l}73.9 \pm 4.9 \\
66-82\end{array}$ & $\begin{array}{l}\text { GF scaling } \\
\text { Anticipatory control }\end{array}$ & $\begin{array}{l}\text { Coordination of GF and transmitted } \\
\text { force during dynamic 2-digit force } \\
\text { tracking }\end{array}$ & $\begin{array}{l}\uparrow \text { Slip force } \\
\text { No age effect in ratio of grip to applied force } \\
\text { GF modulated in parallel with applied force }\end{array}$ \\
\hline
\end{tabular}


Table 1 (continued)

\begin{tabular}{|c|c|c|c|c|}
\hline $\begin{array}{l}\text { Authors and } \\
\text { year }\end{array}$ & Age, years ${ }^{1}$ & Topic & Measurement and task & Main finding in elderly \\
\hline $\begin{array}{l}\text { Cole et al. [37], } \\
1998\end{array}$ & $\begin{array}{l}74 \pm 6.7 \\
65-86\end{array}$ & $\begin{array}{l}\text { Temporal aspects of } \\
\text { grasp control }\end{array}$ & $\begin{array}{l}\text { Temporal force parameters during } \\
\text { grasp, lift and transport of small object } \\
\text { with and without vision }\end{array}$ & $\begin{array}{l}\uparrow \text { Duration of grasp and lift phase } \\
\text { Without vision both groups } \uparrow \text { grasp and lift } \\
\text { duration } \\
\text { Elderly proportionally same increase in duration } \\
\text { as young }\end{array}$ \\
\hline $\begin{array}{l}\text { Sosnoff and } \\
\text { Newell [40], } \\
2006\end{array}$ & $\begin{array}{l}2 \text { elderly groups: } \\
65.7 \pm 3.1 \\
60-69 \\
75.2 \pm 2.7 \\
70-79\end{array}$ & Force variability & $\begin{array}{l}\text { Force variability during finger tremor, } \\
\text { single-digit, } 2 \text { - and } 3 \text {-digit isometric } \\
\text { submaximal force tracking }\end{array}$ & $\begin{array}{l}\uparrow \text { Amount and structure of force variability in all } \\
\text { tasks except finger tremor }\end{array}$ \\
\hline $\begin{array}{l}\text { Völcker-Rehage } \\
\text { and Alberts [41], } \\
2005\end{array}$ & $\begin{array}{l}71.1 \pm 2.4 \\
67-75\end{array}$ & Force variability & $\begin{array}{l}\text { GF modulation (accuracy) during } \\
\text { 2-digit sine wave tracking at } \\
\text { submaximal forces; effect of practice } \\
\text { on GF modulation }\end{array}$ & $\begin{array}{l}\uparrow \text { GF variability in force generation and release } \\
\text { phase } \\
\text { Improvement with practice, albeit less in lower } \\
\text { forces (during force release) }\end{array}$ \\
\hline $\begin{array}{l}\text { Keogh et al. [42], } \\
2006\end{array}$ & $75.7 \pm 2.5$ & $\begin{array}{l}\text { Force variability } \\
\text { Anticipatory control } \\
\text { Force moments } \\
\text { and direction }\end{array}$ & $\begin{array}{l}\text { Inter-digit coupling during } 3 \text {-digit } \\
\text { submaximal force tracking using } \\
\text { constant and sine wave force profiles, } \\
\text { varying force levels }\end{array}$ & $\begin{array}{l}\uparrow \text { Force variability } \\
\uparrow \text { Age difference during sine wave tracking and } \\
\text { at low force levels } \\
\downarrow \text { Strength of inter-digit coupling in sine wave } \\
\text { tracking } \\
\downarrow \text { Correlation and } \uparrow \text { time lag between target force } \\
\text { and middle finger force }\end{array}$ \\
\hline $\begin{array}{l}\text { Völcker-Rehage } \\
\text { et al. [43], } 2006\end{array}$ & $\begin{array}{l}69.9 \pm 3.5 \\
65-77\end{array}$ & Force variability & $\begin{array}{l}\text { Force variability during constant } \\
\text { submaximal } 2 \text {-digit force tracking in } \\
\text { single and dual-task condition }\end{array}$ & $\begin{array}{l}\text { No age effect in GF variability during single task } \\
\uparrow \text { Variability in dual-task } \\
\text { Age difference } \uparrow \text { as second task difficulty } \uparrow\end{array}$ \\
\hline $\begin{array}{l}\text { Cole and Rotella } \\
{[48], 2002}\end{array}$ & $\begin{array}{l}\text { Experiment } 1: 74.6 \\
\text { Experiment } 2: 80\end{array}$ & Anticipatory control & $\begin{array}{l}\text { GF coordination (scaling) during } \\
\text { grasp and lift of objects of varying } \\
\text { texture (exp. 1) and weight (exp. } 2 \text { ); } \\
\text { object properties color-coded or not }\end{array}$ & $\begin{array}{l}\uparrow \mathrm{GF} \\
\text { No use of color codes to scale GF }\end{array}$ \\
\hline $\begin{array}{l}\text { Cole et al. [52], } \\
\text { in press }\end{array}$ & $\begin{array}{l}74 \\
65-83\end{array}$ & $\begin{array}{l}\text { Force moments } \\
\text { and direction }\end{array}$ & $\begin{array}{l}\text { Applied forces to rod, hand } \\
\text { orientation when sliding nut from rod }\end{array}$ & $\begin{array}{l}\uparrow \text { Vertical lifting forces } \\
\uparrow \text { Hand roll } \\
\uparrow \text { Movement duration }\end{array}$ \\
\hline
\end{tabular}

GF = Grip force; IF = inertial force; SM = safety margin; LF = load force; $\uparrow=$ increase; $\downarrow$ = decrease

${ }^{1}$ Mean \pm standard deviation and range.

grasp $[2,24,40,41]$. Also in young participants, greater variability is observed at lower target levels; however, in the young the finding is less consistent across studies, and the variability increases to a lesser extent than in the elderly $[24,41]$. Moreover, differences of force variability associated with aging are seen consistently during multidigit object manipulation $[30,40,42]$ suggesting that controlling an increased number of effectors interferes with grip force steadiness in the elderly [42]. Keogh et al. [42] reported increased force variability in the elderly during a 3-digit force tracking task where the total force applied by the 3 digits had to match a target force. The variability was even more pronounced during sine wave tracking compared to generating a constant force, suggesting that the requirement for ongoing grip force modification increases the demands for grasp control in the elderly [24, $41,42]$.

The effects of task difficulty on age-related differences in grip force variability has also been demonstrated by Voelcker-Rehage et al. [43]. They found that during a task requiring maintenance of a constant grip force, no agerelated differences between young and elderly participants were observed. However, when they performed a second (cognitive) task, the elderly had significantly greater grip force variability than the young [43]. This finding supports the notion that increased processing (attentional) demands interfere with grasp ability in the elderly and are in line with well-documented performance 
declines in elderly when performing 2 tasks at the same time (dual-task) [44]. A paradigm studying grip force control under dual-task conditions seems particularly relevant since daily activities often require attention sharing between the grasp manipulation and a second cognitive or motor task.

More recently, aging has been associated not only with changes in the amount of variability (as in the studies cited above) but also with changes in the structure of variability [40]. Specifically, Sosnoff and Newell [40] showed that the frequency domain of variability during a force tracking task undergoes age-related changes. When transforming the force signal into its frequency domain using fast Fourier analysis, the elderly participants showed a steeper slope in their frequency profile compared to the young during 2- and 3-digit force tracking. The steeper slope suggests an increased frequency-dependent structure of the force signal with aging [40]. Moreover, measures of the structure of variability are suggested to be more sensitive in detecting age differences compared to simple measures quantifying the amount of variability [40].

In contrast to the tasks described above, elderly and young individuals show a comparable amount of grip force variability during simple 2-digit grasp manipulations when the object is held in the air $[23,27]$ and during constant force tracking at relatively high force levels (8$20 \mathrm{~N})[2,23,24,43]$ and/or short task durations [23]. While these findings highlight the importance of considering context when examining age-related processes [45], one could also conclude that increased variability in force output is not a major contributor to difficulties encountered during functional object grasp and lift. Whether or not there is a difference between the elderly and young during simple object grasp and hold in the more sensitive measure of variability, the structure of variability [40] remains to be determined.

In addition to its task dependency, variability in force output may also reflect neurophysiologic changes in the 'pooled behavior' of motor units (i.e., the frequency of the EMG output) [45] and/or changes at the individual motor unit level $[46,47]$. For example, it has been proposed that the death of motor neurons associated with a degeneration of homologous motor units and the following reinnervation of some of these motor units by neighboring motor neurons leads to difficulties in fine tuning at low amplitude forces. Moreover, such motor unit reorganization may result in irregularly discharging firing rates particularly at low force levels $[46,47]$ as needed in grasp manipulations.

Finger Force Coordination Underlying

Object Manipulation in the Elderly
Age-Related Changes in Anticipatory Force Control

Most studies suggest that anticipatory mechanisms of grasp control are marginally, if at all, impaired in the elderly [25-27, 29, 34, 42, 48]. Both during the establishment of the grasp and during object lift, elderly participants are able to scale their grip forces according to the object's weight and its surface properties [27-29]. Moreover, when object properties are randomly varied elderly use object sensory information from previous trials similar to young participants $[28,29,48]$. Both observations indicate an intact use of internal representations of varying object weights and surfaces during grasp and lift movements.

Anticipatory force coupling is also maintained during sine wave force tracking using 2-digit grasp [34, 41] and while maintaining a constant force using 3-digit grasp [42]. However, when using a 3-digit grasp and tracking a sine wave [42], age-related changes in the force coupling begin to emerge. In particular, the coupling between the target force and the middle finger force was weaker in the elderly. No age-related differences were observed in the other digits [42]. It is conceivable that with increased task difficulty and an increased number of digits to coordinate, anticipatory control mechanisms, as seen before in force variability, become increasingly susceptible to agerelated changes.

To date, only 2 studies examined dynamic actions with a hand-held object in the elderly. Similar to the tasks described above, when an object is moved in space, anticipatory control is either normal or only slightly impaired in the elderly. Gilles and Wing [26] and Danion et al. [25] examined vertical point-to-point [26] and horizontal cyclical movements [25], respectively, and found that the grip and load forces fluctuated in parallel. These findings indicate that the elderly are able to incorporate the motor command of the arm into their internal representation just as well as the young. However, as movement conditions become more complex, elderly participants show differences in anticipatory grasp control. Danion et al. [25] had young and elderly participants perform cyclic anterior-posterior arm movements with a hand-held object under varying external force fields resulting in varying load force frequencies at the object-digit interface. The grip force adjustments were delayed and the coupling of grip and load forces was weaker in the elderly when the frequencies of the arm movement and the load force differed. Danion et al. [25] suggested that anticipatory control starts to deteriorate when environmental constraints alter the load force frequency at the hand-held object. A conclusion that anticipatory control during dynamic 
tasks is largely intact and only susceptible to changes under certain environmental constraints, however, would be premature given a fairly young mean age of the elderly; $66 \pm 3.6$ years in the study by Danion et al. [25], and $64.5 \pm 3.8$ years in Gilles and Wing [26]. Because agerelated changes occur progressively, and are more pronounced in more elderly participants $[27,28]$, further study with a wider age range is required.

It is important to note that a prerequisite for anticipatory control for new objects is the ability to use vision to quickly establish relationships between object properties and the forces required to skillfully handle them. Cole et al. [48] showed age-related differences when learning associations between visual cues and object properties. When lifting color-coded objects of different weights or surfaces, young participants could associate colors assigned to weight and surface texture, and appropriately scaled their grip force to the respective object property. However, the elderly participants did not take advantage of the color-surface or color-weight association to predict object properties and instead used a default force scaling [48]. Importantly, vision in the elderly was reported to be normal or corrected to normal, and the elderly participants were able to correctly identify the colors used in the experiment. Hence, the impairment in the color-weight associations is not likely due to age-related changes in vision. Rather, this suggests that anticipatory mechanisms may not be used as efficiently when new associations need to be formed, as would occur when manipulating unfamiliar objects. Thus one could postulate that dexterity problems would be exacerbated in the elderly when they encounter unfamiliar objects. Nevertheless, many visual cues are less ambiguous than color, including size, density and mass distribution, and the extent to which these meaningful cues can be used is largely unknown.

In summary, anticipatory aspects of grasp control associated with the utilization of memory representations seem to be only minimally affected by aging during simple object manipulations. However, small changes in anticipatory control emerge as task difficulty increases. The functional significance of impaired anticipatory control includes an increased likelihood of object dropping. Moreover, it increases the reliance on the sensory feedback system [28] which already functions at a suboptimal level in the elderly.

\section{Temporal Aspects of Force Coordination during Object Manipulation}

The effects of aging on the temporal aspects of grip force control have been observed across a wide variety of tasks, including: object grasp and lift of varying surfaces [27-29], grasping and transporting small objects [37], isometric force tracking [24], and unpredictable load changes [31]. For the most part, the early phases of the task were most vulnerable to age-related changes. Specifically, elderly participants showed increased durations of the preload and loading phase [28], and increased latencies in grip force response to new surfaces [29] or load changes [31]. Because sensory information is particularly important in the early phases of the grasp-lift tasks as described above [12], it has been proposed that these age-related prolongations are the result of deterioration in tactile sensation [28]. However, Cole et al. [37], who examined a simple, predictable task, challenged the idea that temporal changes in the elderly are related to the deterioration of tactile sensation at the fingertips. In this experiment, the availability of vision was manipulated. The authors assumed that decreasing visual input would increase the reliance on tactile information during the grasp task. Such deprivation of visual input would therefore unravel possible contributions of tactile impairments to age-related changes in precision grasping. While the elderly performed the task more slowly under both conditions, when vision was absent, the slowing of the elderly was proportionally the same as that of the young. Thus, reliance on only tactile information did not slow down the elderly more than the young. The authors concluded that although tactile sensation was impaired, it was sufficient for completing the temporal aspects of simple predictable tasks in which tactile information is not crucial [37]. The longer movement durations in the elderly may therefore be due to a general behavioral slowing of motor performance [37].

Tactile information, however, seems to depend on the nature of the task. For example, when surface texture is varied unpredictably, grip force adjustments to a new surface are delayed by about $100 \mathrm{~ms}$ in the elderly compared to the young [29]. Similarly, during unpredictable small load perturbations, elderly grip response latencies are amplified [31]. Both findings coincided with an elevated force detection threshold in the elderly underlining the relationship between tactile information processing and grip force delays. The response latencies of elderly and young, however, did not differ when the unpredictable load changes were large and rapid. The latter finding confirms the crucial role of force detection thresholds mediated by mechanoreceptors in the fingertips [31].

Cole et al. [29, 37, 49] suggested that the role of impaired tactile information might change with the task context. Age-related deterioration of tactile sensation will 
have a detrimental effect especially during tasks where sensory information is crucial, such as during unpredictable changes of friction [29] or load [31]. In a functional context, these effects may include the fingers sliding from the object when it is more slippery than expected, or an increased likelihood of dropping the object in unfamiliar and/or unpredictable situations.

\section{Force Moments, Force Direction, and Force Sharing Patterns}

To maintain an upright orientation of an object with symmetrical mass distribution during a 2-digit precision grasp, the force magnitudes of the thumb and index finger need to be equal and opposite [12], resulting in a zero net external moment. Likewise, in a multi-digit grasp, the forces of all digits opposing the thumb counteract the force exerted by the thumb $[42,50]$. Winges and Santello [50] described a default strategy by which finger forces covary synchronously during object holding. Recent reports showed impairment in this inter-digit coordination associated with the ability to produce and maintain accurate external moments of forces in the elderly [30,42]. For example, Shim et al. [30] reported greater moments in the digit opposing the required force ('antagonistic moment') in the elderly. Moreover, elderly showed an increase in the index and a decrease in the middle finger contribution to the total force [42].

While the differences in multi-digit coordination and moment control could lead to unwanted object tilt, and hence, may help explain impaired manual dexterity, it is important to note that the differences in the inter-digit coupling were observed during force tracking, not object hold. Moreover, in the study by Shim et al. [30] gravitational forces did not have to be taken into account. McIsaac et al. [51] showed that participants' ability to produce appropriate force sharing patterns is decreased when young participants are asked to reproduce a target force versus actually holding an object [51]. In light of these findings, the results from the multi-digit grasping experiments in the elderly described above necessitate a careful interpretation as far as functionally relevant deficits as they may be influenced by task context. Nevertheless, findings by Cole et al. [52] using more functional tasks support the idea that controlling external moments during object manipulation is subject to change with age. Specifically, the elderly showed a greater hand roll compared to the young when sliding nuts of different shapes from a rod. Coinciding with an increased hand roll, the elderly also applied increased vertical forces to the rod as they removed the nut [52]. The authors suggested that in part, such increased lifting forces may be a result of impairments in sensing the forces applied at the fingertips. In addition, the elderly participants showed increased movement durations in both tasks. Changes in the ability to detect force direction may underlie difficulties in controlling moments $[42,49]$, and in turn lead to increased movement times observed in the elderly [49] (for an elaborate discussion on the relationship between controlling force moments, tactile sensation and movement duration, see Cole [49]).

Difficulties in maintaining object orientation may also contribute to the grip force increases observed in the elderly. When required to produce a stable force moment during a 5-digit grasp, the elderly showed increased antagonist moments (i.e., moments opposing the desired direction) compared to young control participants [30]. Shim et al. [30] suggested that this increased antagonist moment production and the stronger central commands associated with it may yield grip force increases in all digits (not only the ones producing the antagonist moment). Hence, grip force increases could also be interpreted as an adaptive strategy reducing potentially negative consequences of impairments associated with aging such as improper moment control [30].

\section{Summary, Conclusion and Future Research Directions}

Grasping in the elderly appears to be characterized by excessive grip force magnitudes. These force increases compensate for the effects of increased skin slipperiness and reduced tactile information, and may characterize a strategy to avoid object slips due to delayed grip force responses when contact surface or load change unpredictably. At the same time, the elderly show relatively intact anticipatory control during simple grasp manipulations. With increasing task complexity, however, age-related changes in anticipatory control emerge.

The relationship between task complexity and degree of age-related changes suggests that results from simple, laboratory-based tasks are only partially suitable for explaining impairments observed in complex functional activities. Most laboratory-based paradigms have been limited to seated grasping, focus on just one task and often eliminate gravity and/or behavioral consequences. In everyday life, gravity is always present and there are behavioral consequences to unsuccessful grasp control. Moreover, grasp control often involves the coordination of multiple body segments, and occurs simultaneously 
with a second cognitive or motor task. Hence, in a next step to understand mechanisms of impaired dexterity, experimental paradigms should be expanded to include these aspects of functional tasks. Such tasks may include the manipulation of a fluid-filled container using a multidigit grasp or carrying an object while walking. The latter task, investigated before in a healthy young population [21], is a dynamic task involving the coordination of multiple body segments (i.e., inertial force changes on the object are induced by whole-body movement), moment-tomoment grasp adjustments, and requires attention sharing between walking and grasping [21].
Research that integrates laboratory-based and complex functional tasks may help to better understand agerelated changes in manual dexterity. Subsequently, these findings could be used in clinical settings to develop treatment approaches to improve grasp control during behaviorally meaningful tasks. The aim of such treatment would be to maintain or restore manual dexterity in a context suitable for independence in activities of daily living.

\section{References}

1 Desrosiers J, Hebert R, Bravo G, Rochette A: Age-related changes in upper extremity performance of elderly people: A longitudinal study. Exp Gerontol 1999;34:393-405.

$\checkmark 2$ Ranganathan VK, Siemionow V, Sahgal V, Yue GH: Effects of aging on hand function. J Am Geriatr Soc 2001;49:1478-1484.

-3 Spector WD, Fleishman JA: Combining activities of daily living with instrumental activities of daily living to measure functional disability. J Gerontol B Psychol Sci Soc Sci 1998;53:S46-S57.

4 Desrosiers J, Hebert R, Bravo G, Dutil E: The Purdue Pegboard Test: normative data for people aged 60 and over. Disabil Rehabil 1995; 17:217-224

5 Hackel ME, Wolfe GA, Bang SM, Canfield JS: Changes in hand function in the aging adult as determined by the Jebsen Test of Hand Function. Phys Ther 1992;72:373-377.

6 Desrosiers J, Hebert R, Bravo G, Dutil E: Upper extremity performance test for the elderly (TEMPA): normative data and correlates with sensorimotor parameters. Arch Phys Med Rehabil 1995;76:1125-1129.

7 Shiffman LM: Effects of aging on adult hand function. Am J Occup Ther 1992;46:785792.

-8 Falconer J, Hughes SL, Naughton BJ, Singer R, Chang RW, Sinacore JM: Self report and performance-based hand function tests as correlates of dependency in the elderly. J Am Geriatr Soc 1991;39:695-699.

-9 Williams ME, Hadler NM, Earp JAL: Manual ability as a marker of dependency in geriatric women. J Chronic Dis 1982;35:115-122.

10 Carmeli E, Patish H, Coleman R: The aging hand. J Gerontol A Biol Sci Med Sci 2003;58: 146-152.

11 Johansson RS, Flanagan RJ: Coding and use of tactile signals from the fingertips in object manipulation tasks. Nat Rev Neurosci 2009; 10:345-359.
12 Johansson RS, Westling G: Roles of glabrous skin receptors and sensorimotor memory in automatic control of precision grip when lifting rougher or slippery objects. Exp Brain Res 1984;56:550-564.

13 Salimi I, Hollender I, Frazier W, Gordon AM: Specificity of internal representations underlying grasping. J Neurophysiol 2000; 84:2390-2397.

14 Gordon AM, Forssberg H, Johansson RS, Westling G: Visual size cues in the programming of manipulative forces during precision grip. Exp Brain Res 1991;83:477-482.

15 Gordon AM, Westling G, Cole KJ, Johansson RS: Memory representations underlying motor commands used during manipulation of common and novel objects. J Neurophysiol 1993;69:1789-1796.

16 Flanagan RJ, Tresilian JR: Grip-load force coupling: a general control strategy for transporting objects. J Exp Psychol Hum Percept Perform 1994;20:944-957.

17 Diermayr G, Gysin P, Hass CJ, Gordon AM: Grip force control during gait initiation with a hand-held object. Exp Brain Res 2008;190: 337-345.

18 Macefield VG, Johansson RS: Control of grip force during restraint of an object held between finger and thumb: responses of muscle and joint afferents from the digits. Exp Brain Res 1996;108:172-184.

19 Dimitriou M, Edin BB: Discharges in human muscle receptor afferents during block grasping. J Neurosci 2008;28:12632-12642.

20 Nowak DA, Hermsdorfer J, Glasauer S, Philipp J, Meyer L, Mai N: The effects of digital anesthesia on predictive grip force adjustments during vertical movements of a grasped object. Eur J Neurosci 2001;14:756762.

21 Gysin P, Kaminski TR, Hass CJ, Grobet CE, Gordon AM: Effects of gait variations on grip force coordination during object transport. J Neurophysiol 2008;100:2477-2485.
22 Nowak D, Hermsdörfer J: Predictive and reactive control of grasping forces: on the role of the basal ganglia and sensory feedback. Exp Brain Res 2006;173:650-660.

23 Cole K, Beck C: The stability of precision grip force in older adults. J Mot Behav 1994;26: 171-177.

24 Lindberg P, Ody C, Feydy A, Maier M: Precision in isometric precision grip force is reduced in middle-aged adults. Exp Brain Res 2009;193:213-224.

25 Danion F, Descoins M, Bootsma RJ: Aging affects the predictive control of grip force during object manipulation. Exp Brain Res 2007;180:123-137.

26 Gilles MA, Wing AM: Age-related changes in grip force and dynamics of hand movement. J Mot Behav 2003;35:79-85.

27 Cole K: Grasp force control in older adults. J Mot Behav 1991;23:251-258.

28 Kinoshita H, Francis PR: A comparison of prehension force control in young and elderly individuals. Eur J Appl Physiol 1996;74: 450-460.

29 Cole KJ, Rotella DL, Harper JG: Mechanisms for age-related changes of fingertip forces during precision gripping and lifting in adults. J Neurosci 1999;19:3238-3247.

30 Shim J, Lay B, Zatsiorsky V, Latash M: Agerelated changes in finger coordination in static prehension tasks. J Appl Physiol 2004; 97:213-224.

- 31 Cole KJ, Rotella DL: Old age affects fingertip forces when restraining an unpredictably loaded object. Exp Brain Res 2001;136:535542.

32 Mallau S, Simoneau M: Aging reduces the ability to change grip force and balance control simultaneously. Neurosci Lett 2009;452: 23-27.

33 Hegner G, Wienert V, Sick H, Gahlen W: Skin humidity. Fortschr Med 1981;99:486490 . 
34 Lowe BD: Precision grip force control of older and younger adults, revisited. J Occup Rehabil 2001;11:267-279.

35 Bruce MF: The relation of tactile thresholds to histology in the fingers of elderly people. J Neurol Neurosurg Psychiatry 1980;43:730734 .

36 Shaffer SW, Harrison AL: Aging of the somatosensory system: a translational perspective. Phys Ther 2007;87:193-207.

37 Cole KJ, Rotella DL, Harper JG: Tactile impairments cannot explain the effect of age on a grasp and lift task. Exp Brain Res 1998;121: 263-269.

38 Grabiner MD, Enoka RM: Changes in movement capabilities with aging. Exerc Sport Sci Rev 1995;23:65-104.

-39 Missenard O, Mottet D, Perrey S: The role of cocontraction in the impairment of movement accuracy with fatigue. Exp Brain Res 2008;185:151-156.

40 Sosnoff JJ, Newell KM: The generalization of perceptual-motor intra-individual variability in young and old adults. J Gerontol B Psychol Sci Soc Sci 2006;61:P304-P310.
41 Voelcker-Rehage C, Alberts JL: Age-related changes in grasping force modulation. Exp Brain Res 2005; 166:61-70.

42 Keogh J, Morrison S, Barrett R: Age-related differences in inter-digit coupling during finger pinching. Eur J Appl Physiol 2006;97: 76-88.

43 Voelcker-Rehage C, Stronge AJ, Alberts JL: Age-related differences in working memory and force control under dual-task conditions. Neuropsychol Dev Cogn 2006;13:366384.

44 Woollacott M, Shumway-Cook A: Attention and the control of posture and gait: a review of an emerging area of research. Gait Posture 2002;16:1-14

45 Vaillancourt DE, Larsson L, Newell KM: Effects of aging on force variability, single motor unit discharge patterns, and the structure of 10, 20, and $40 \mathrm{~Hz}$ EMG activity. Neurobiol Aging 2003;24:25-35.

46 Enoka RM, Christou EA, Hunter SK, Kornatz KW, Semmler JG, Taylor AM, Tracy BL: Mechanisms that contribute to differences in motor performance between young and old adults. J Electromyogr Kinesiol 2003;13:112.
47 Moritz CT, Barry BK, Pascoe MA, Enoka RM: Discharge rate variability influences the variation in force fluctuations across the working range of a hand muscle. J Neurophysiol 2005;93:2449-2459.

48 Cole KJ, Rotella DL, Harper JG: Old age impairs the use of arbitrary visual cues for predictive control of fingertip forces during grasp. Exp Brain Res 2002;143:35-41.

49 Cole KJ: The effects of aging on sensorimotor control of the hand; in Nowak DA, Hermsdoerfer J (eds): Sensorimotor Control of Grasping. Cambridge, Cambridge University Press, 2009, pp 250-266.

50 Winges SA, Santello M: From single motor unit activity to multiple grip forces: mini-review of multi-digit grasping. Integr Comp Biol 2005;45:679-682

51 McIsaac TL, Santello M, Johnston JA, Zhang W, Gordon AM: Task-specific modulation of multi-digit forces to object texture. Exp Brain Res 2009;194:79-90.

52 Cole KJ, Cook KM, Hynes SM, Darling WG Slowing of dexterous manipulation in old age: force and kinematic findings from the 'nut-and-rod' task. Exp Brain Res 2009 [Epub ahead of print PMID: 19795110]. 